\title{
Reliability and validity of the Farsi version of the Patient Health Questionnaire-9 (PHQ-9) with Iranian psychiatric outpatients
}

\author{
Confiabilidade e validade da versão persa do Patient Health Questionnaire-9 \\ (PHQ-9) em pacientes psiquiátricos ambulatoriais iranianos
}

Mahboubeh Dadfar, ${ }^{1}$ Zornitsa Kalibatseva, ${ }^{2}$ David Lester $^{2}$

\begin{abstract}
Introduction: The Patient Health Questionnaire-9 (PHQ-9) is a brief screening and diagnostic tool for depression. It has been used in research and clinical practice in primary care and other clinical and non-clinical settings. The PHQ-9 has not had its validity examined in psychiatric and psychological settings in Iran.

Methods: A cross-sectional study was conducted to investigate the validation of the Farsi version of the PHQ-9. A convenience sample of 130 Iranian volunteer psychiatric outpatients was selected from psychiatric and psychological clinics. They completed the PHQ-9, the Patient Health Questionnaire-15 (PHQ15), the World Health Organization-five Well-Being Index (WHO5 ), and the short form of the Beck Depression Inventory-13 (BDI13). Data were analyzed by descriptive statistics, Cronbach's a, Pearson correlation coefficient, principal component analysis, exploratory factor analysis, and confirmatory factor analysis.

Results: Mean score of the PHQ-9 was 12.83 (standard deviation $=6.25$ ), indicating moderately severe depression in the sample. Cronbach's a coefficient for PHQ-9 was 0.88 , and oneweek test-retest reliability 0.79 . The PHQ-9 correlated 0.64 with PHQ-15, -0.35 with WHO-5, and 0.70 with BDI-13, indicating good construct and criterion-related validity. The results of the factor analysis of PHQ-9 items identified and confirmatory factor analysis confirmed a single factor labeled general depression.

Conclusions: The PHQ-9 appears to have a unidimensional structure, adequate validity and reliability, and can be useful in epidemiological/research settings. Based on previous literature and on the present findings, the PHQ-9 may have applicability to other contexts in the studied population, but this needs to be confirmed by other studies.
\end{abstract}

Keywords: Depression, validity, reliability, factorial structure, Patient Health Questionnaire-9, psychiatric outpatients, Iran.

\section{Resumo}

Introdução: O Patient Health Questionnaire-9 (PHQ-9) é uma ferramenta breve de triagem e diagnóstico para depressão. Tem sido usado em pesquisa e na prática clínica primária e em outros contextos clínicos e não clínicos. O PHQ-9 não teve sua validade examinada em contextos psiquiátricos e psicológicos no Irã.

Métodos: Um estudo transversal foi conduzido para investigar a validação da versão persa do PHQ-9. Uma amostra de conveniência de 130 pacientes psiquiátricos ambulatoriais iranianos foi selecionada em clínicas psiquiátricas e psicológicas. Os pacientes completaram o PHQ-9, Patient Health Questionnaire-15 (PHQ-15), the World Health Organization-five Well-Being Index (WHO-5) e a forma abreviada do Beck Depression Inventory-13 (BDI-13). Os dados foram analisados por estatística descritiva, a de Cronbach, coeficiente de correlação de Pearson, análise de componentes principais e análise fatorial exploratória e confirmatória.

Resultados: O escore médio do PHQ-9 foi 12,83 (desvio padrão $=6,25$ ), indicando depressão moderadamente severa na amostra. $\mathrm{O}$ a de Cronbach para PHQ-9 foi 0,88, e a confiabilidade teste-reteste de uma semana 0,79. O PHQ-9 apresentou correlação de 0,64 com PHQ-15, -0,35 com WHO-5 e 0,70 com BDI-13, indicando boa validade do construto e dos critérios relacionados. Os resultados da análise fatorial dos itens do PHQ9 identificaram, e a análise fatorial confirmatória confirmou, um único fator, chamado depressão geral.

Conclusões: O PHQ-9 parece ter uma estrutura unidimensional, validade e confiabilidade adequadas, e pode ser útil em contextos epidemiológicos e de pesquisa. Com base na literatura prévia e neste estudo, o PHQ-9 pode ter aplicabilidade em outros contextos na população estudada, mas isso precisa ser confirmado.

Descritores: Depressão, validade, confiabilidade, estrutura fatorial, Patient Health Questionnaire-9, pacientes psiquiátricos ambulatoriais, Irã.

\footnotetext{
${ }^{1}$ School of Health, School of Behavioral Sciences and Mental Health - Tehran Institute of Psychiatry, International Campus, School of Public Health, Iran University of Medical Sciences, Tehran, Iran. ${ }^{2}$ Psychology Program, Stockton University, Galloway, NJ, USA.

Submitted Apr 13 2017, accepted for publication Aug 232017.

Suggested citation: Dadfar M, Kalibatseva Z, Lester D. Reliability and validity of the Farsi version of the Patient Health Questionnaire-9 (PHQ-9) with Iranian psychiatric outpatients. Trends Psychiatry Psychother. 2018;40(2):144-151. http://dx.doi.org/10.1590/2237-6089-2017-0116
} 


\section{Introduction}

Depression is an important public health problem and the most common mental disorder in primary care. It is estimated that depression will be the second biggest cause of disability worldwide by $2020 .{ }^{1}$ The symptoms of depression are specific (depressed mood, loss of interest in activities, impaired concentration, feelings of worthlessness or guilt, and suicidal ideation), and may include general symptoms of distress found not only in depression, but also in other psychiatric and medical syndromes (somatic symptoms, abdominal pain, back pain, change in weight or appetite, constipation, fatigue, headache, insomnia or hypersomnia, joint pain, neck pain, and weakness). ${ }^{2}$ Depression is correlated with several chronic and other illnesses, and also with factors that increase the risk for those illnesses. Some risk factors for depression include younger age, female sex, single/divorced/widowed status, low income, job loss, chronic medical illness, chronic minor daily stress, chronic pain syndrome, family history of depression, low self-esteem, low social support, prior depression, and traumatic brain injury. ${ }^{2,3}$

The economic burden of depression includes workplace costs, direct costs and suicide- related costs. Studies have reported a prevalence of mood disorders of $9.3 \%$, and of major depression disorder (MDD) of $8.2 \%{ }^{4}$; depression has been shown to be associated with suicide thoughts and attempted suicide in Iranian samples. ${ }^{5,6}$

Many tools have been developed for depression screening, e.g. the Beck Depression Inventory (BDI), Center for Epidemiological Studies - Depression Scale (CES-D), Geriatric Depression Scale (GDS), Hospital Anxiety and Depression Scale (HADS), and Primary Care Evaluation of Mental Disorders - Mood Module (PRIME-MD). ${ }^{1,7}$

The PRIME-MD is a rapid procedure and diagnostic instrument designed to identify individuals with mental disorders in primary care. The Mood Module was developed to diagnose depression and depressive symptoms according to the Diagnostic and Statistical Manual of Mental Disorders, 3rd edition, revised (DSMIII-R), now updated to DSM-5.2,8 The PRIME-MD is a two-stage diagnostic tool comprised of a screening instrument (Patient Questionnaire [PQ]) and a structured interview (Clinician Evaluation Guide [CEG]). The two components of the original PRIME-MD were combined into a three- and four-page, self-administered version called PRIME-MD Patient Health Questionnaire (PHQ). The PHQ has modules for five common types of mental disorders: depressive, anxiety, somatoform, alcohol, and eating disorders. A two-page version, the
Brief $\mathrm{PHQ}$, has also been developed. The Patient Health Questionnaire-9 (PHQ-9) is the depression module of the PHQ. ${ }^{9-11}$

The PHQ-9 is a self-report screening tool to aid in diagnosing and measuring the severity of depression and dysthymic disorder. ${ }^{8,10-17}$ The PHQ-9 has been utilized in research, clinical practice, and epidemiological surveys of mental health. ${ }^{18-27}$ It can be administered in person or over the telephone. ${ }^{28}$

The PHQ-9 is free to users and is available in English and over 30 other languages. It has been validated in populations such as Brazilian, Thai, Greek, Saudi Arabian, Taiwanese, Chinese, Korean, Spanish, Mexican, French, Australian, Nigerian, Turkish, Japanese, Swahili, Sinhala, and Portuguese. ${ }^{29-48}$ The PHQ-9 has been translated into Farsi and culturally adapted to Iranian patients with type 2 diabetes. ${ }^{49}$ However, the PHQ9 has not been validated among Iranian psychiatric outpatients.

There has been a resurgence of interest in depression in medical illnesses (especially advanced disease), given recent developments in measurement tools and psychotherapeutic treatments to reduce depressive symptoms in patients and families. This work is important to support and this manuscript offers a useful application of the PHQ-9 in Farsi, to promote the study of depression in individuals who suffer from the mood and emotional difficulties involved in confronting stressors and daily hassles, and indeed may be burned out by them over time.

There are compelling reasons for using the $\mathrm{PHQ}-9$ as a measure for depression, since cultural, religious, and ethnic factors can influence the severity of depression. Despite the good characteristics of the PHQ-9 and its applicability in English-speaking persons and several other different languages, there are no published studies on the validation of the PHQ-9 for Iranian psychiatric outpatients. The PHQ-9 would be useful in personality research and in clinical practice, but there is a need to estimate the psychometric properties of the instrument. Thus, the aim of the present study was to examine and explore the validity, reliability and factorial structure (exploratory and confirmatory factor analysis to test for previous factor structures) of the PHQ-9 to assess construct validity in a clinical sample of Iranian psychiatric outpatients.

\section{Methods}

\section{Participants}

A convenience sample of 130 Iranian volunteer psychiatric outpatients was selected from the psychiatric 
and psychological clinics at the School of Behavioral Sciences and Mental Health - Tehran Institute of Psychiatry affiliated with the Iran University of Medical Sciences. Patients were invited to voluntarily participate in the study after they completed a psychiatric interview with one psychiatrist. All patients provided written consent. The study protocol was approved by an institutional review board.

The patients completed the Farsi versions of the PHQ-9, the Patient Health Questionnaire-15 (PHQ-15), the World Health Organization-five Well-Being Index (WHO-5), and the short form of the Beck Depression Inventory-13 (BDI-13).

\section{Measures}

The Patient Health Questionnaire-9 (PHQ-9)

The PHQ-9 is a self-administered scale used for screening, assessing, and monitoring depression severity. ${ }^{50}$ The PHQ-9 has nine items and the answers refer to the past two weeks. Nine items assess symptoms, and one of them assesses functional impairment. Each item is scored using a 4-point Likert scale ranging from 0 to 3: not at all (0), several days (1), more than half the days (2), and nearly every day (3). The PHQ-9 total score for the nine items may range from 0 to 27 . A score $\geq 15$ is classified as major depression, and $\geq 20$ as severe major depression. The diagnostic validity of the PHQ-9 for MDD has been confirmed in eight primary care and seven obstetric clinics studies. ${ }^{10,51}$ Different cut-off points for different versions of the PHQ-9 have already been proposed, ranging from $\geq 9$ to $\geq 13$ (sensitivity ranging from 73.8 to $77.5 \%$ and specificity from 76.2 to $0.97 \%) .{ }^{22,46,49}$ Xiong et al. ${ }^{52}$ reported good psychometric properties of the PHQ-9 for major depression in Chinese outpatients with multiple somatic symptoms. Solem et al. ${ }^{53}$ found a Cronbach's a of 0.88 for the PHQ-9 in a Norwegian-speaking community sample.

\section{The Patient Health Questionnaire-15 (PHQ-15)}

The PHQ-15 is a self-administered scale used to screen for somatoform disorders. It covers 15 somatic symptoms, such as stomach pain, back pain, and headaches, and is scored using a 3-point Likert scale: not bothered at all (0), bothered a little (1), and bothered a lot (2). PHQ-15 scores of 5, 10, and 15 represent cutoff points for low, medium, and high somatic symptom severity, respectively. Research indicates high reliability and validity of the PHQ-15 in different samples and various settings. ${ }^{54-62}$ Because somatoform symptoms, such as pain, headaches, trouble sleeping, appetite disturbance, and fatigue or loss of energy may be associated with depression, the patients also answered the PHQ-15.
The World Health Organization-five Well-Being Index (WHO-5)

The WHO-5 is a commonly used measure of subjective psychological and emotional well-being. It has been used as a screening tool for depression and as an outcome instrument in clinical trials. ${ }^{63}$ Each of the five items of the WHQ-5 is rated using a 6-point Likert scale ranging from not present $(0)$ to constantly present (5), with scores ranging from 0 to 25. Acceptable psychometric characteristics of the WHO-5 have been demonstrated in different samples, including Dutch diabetes outpatients, ${ }^{64,65}$ and primary care patients. ${ }^{66}$ The test-retest reliability of the WHO-5 was 0.90 .67 Cronbach's a for the WHO-5 was 0.91 among Iranian psychiatric outpatients. ${ }^{68}$

The short form of the Beck Depression Inventory-13 (BDI-13)

The BDI-13 is a screening tool for depressive disorders. Dadfar \& Kalibatseva69 found good psychometric properties of the BDI-13 with Iranian psychiatric outpatients, including a Cronbach's a of 0.85 and moderate to strong positive associations with measures of mental health.

\section{Statistical analysis}

Data were analyzed by descriptive statistics, Cronbach's a, Pearson correlation coefficient, principal component analysis, exploratory factor analysis, and confirmatory factor analysis. The fit measures of the confirmatory factor analysis results for goodness of fit indices such as the comparative fit index (0.94), Tucker-Lewis index (0.93), and root mean square error (0.06) were good, denoting suitable, adequate and favorable fit measures. Analyses were performed using the Statistical Package for the Social Sciences (SPSS) version 16 and the Lisrel software.

\section{Results}

Table 1 shows descriptive variables of the sample and all questionnaires. The mean score obtained on the PHQ-9 was 12.83 (standard deviation $[S D]=6.25$ ). Mean scores on PHQ-9 items ranged from $0.71(\mathrm{SD}=0.77)$, on suicidality/self-harm, to $1.09(\mathrm{SD}=0.94)$, on fatigue/ decreased energy.

\section{PHQ-9 reliability}

Cronbach's a coefficient for the PHQ-9 was 0.88, indicating high internal consistency (Table 1). Oneweek test-retest reliability was 0.79 . 


\section{PHQ-9 inter-item and item-total score correlations}

Correlations between individual items and the total score ranged from 0.67 for item 3 to 0.81 for item 7 (all significant at 0.01 ), indicating moderate to high associations between each item and the scale total score.

Correlations between items ranged from 0.32 for items 1 and 8, to 0.62 for items 6 and 7 (significant at 0.01 ), indicating moderate association between the items of the scale (Table 2).

\section{PHQ-9 correlations with other questionnaires}

The PHQ-9 score correlated at 0.64 with the PHQ15 , at -0.36 with the $\mathrm{WHO}-5$, and at 0.70 with the BDI-13, indicating moderate to high concurrent validity (Table 2).

\section{PHQ-9 factor analysis}

The criteria used for factor analysis were evaluated using the Kaiser-Meyer-Olkin measure of sampling adequacy (KMO) and Bartlett's test of sphericity. KMO was 0.896 , indicating adequacy of the sample of psychiatric outpatients, and Bartlett's test of sphericity was $515.834(\mathrm{df}=36, \mathrm{p}<0.001)$, indicating that the factor analysis was justified. The results of the exploratory factor analysis on PHQ-9 extracted only one component (factor).

Factor 1 (all 9 items) explained $53.26 \%$ of the observed variance and was labeled general depression (Table 3). The confirmatory factor analysis confirmed this component.

\section{Discussion}

The aim of this study was to examine the psychometric and screening properties for depression of the PHQ-9 in a sample of Iranian psychiatric outpatients. The mean score of the PHQ-9 indicated moderate depression severity in the sample. The lowest mean score was obtained for item 9 ("Thoughts that

Table 1 - Descriptive variables of the sample and all questionnaires

\begin{tabular}{lc}
\hline Sample description & Result \\
\hline Age (years), mean (SD) & $31.40(8.20)$ \\
Mental disorder duration (years), mean (SD) & $7.91(6.94)$ \\
Gender, n (\%) & \\
Male & $4(26.6)$ \\
Female & $96(73.4)$ \\
Marital status, n (\%) & \\
Single & \\
Married & $48(62.4)$ \\
Divorced & $36(29.6)$ \\
Widowed & $8(6.4)$ \\
Education, n (\%) & $10(8)$ \\
High school & \\
Higher education degree & $52(66.6)$ \\
Diagnosis, n (\%) & $48(33.4)$ \\
Anxiety disorder & \\
Depressive disorder & \\
Other mental disorder & \\
Missing data & $43(55.6)$ \\
Questionnaires, mean (SD) [Cronbach's a] & $29(37)$ \\
Patient Health Questionnaire-9 (PHQ-9) & $23(3)$ \\
Patient Health Questionnaire-15 (PHQ-15) & $5.05(6.46)[0.92]$ \\
World Health Organization-five Well-Being Index (WHO-5) \\
Beck Depression Inventory-13 (BDI-13) & $9.65(5.92)[0.80]$ \\
\hline
\end{tabular}

$\mathrm{SD}=$ standard deviation 
you would be better off dead, or of hurting yourself in some way"), and the highest one for item 4 ("Feeling tired or having little energy"). Hanwella et al. ${ }^{46}$ found the items' mean scores ranged from 0.57 to 1.36 , with 0.57 being the lowest item mean, found in patients with MDD. The findings of Torres et al. ${ }^{48}$ showed that overall scores and severity levels were strongly associated with functional and symptom subscales, denoting good construct validity for the PHQ-9. Cronbach's a for the PHQ-9 was 0.88 , and one-week test-retest reliability was 0.79 , indicating good reliability, consistent with research in other countries. ${ }^{46,48,67,70-78}$
In the present sample, the PHQ-9 had moderate to strong positive associations with measures of mental health (PHQ-15 and BDI-13), expect for the negative association with WHO-5, indicating good construct validity. Findings of Dum et al. ${ }^{75}$ showed that the PHQ-9 correlated with BDI-II and with severity levels of alcohol and drug use among substance abuser outpatients.

The convergent validity of the PHQ- 9 has been reported to range from $0.56^{35}$ to $0.74 .{ }^{36}$ According to Zuithoff et al., ${ }^{76}$ the PHQ-9 correlated with functional status measurements, sick days, and number of consultations in the Netherlands primary care. Hyphantis et al. ${ }^{73}$ found that the PHQ-

Table 2 - Pearson correlation coefficients $(r)$ between PHQ-9 items and with other questionnaires

\begin{tabular}{|c|c|c|c|c|c|c|c|c|c|c|}
\hline Questionnaires & PHQ-9 & & & & & & & & & \\
\hline PHQ-15 & 0.649* & & & & & & & & & \\
\hline WHO-5 & $-0.385^{+}$ & & & & & & & & & \\
\hline BDI-13 & $0.702 *$ & & & & & & & & & \\
\hline Items & 1 & 2 & 3 & 4 & 5 & 6 & 7 & 8 & 9 & Total \\
\hline 1 & 1 & & & & & & & & & \\
\hline 2 & $0.518 *$ & 1 & & & & & & & & \\
\hline 3 & $0.475 *$ & $0.455^{*}$ & 1 & & & & & & & \\
\hline 4 & $0.538 *$ & $0.486 *$ & $0.545 *$ & 1 & & & & & & \\
\hline 5 & $0.331 *$ & $0.327 *$ & $0.323 *$ & 0.496* & 1 & & & & & \\
\hline 6 & $0.429 *$ & $0.504 *$ & $0.348^{*}$ & $0.528 *$ & $0.553 *$ & 1 & & & & \\
\hline 7 & $0.542 *$ & $0.525 *$ & $0.437^{*}$ & $0.536 *$ & $0.549 *$ & $0.623^{*}$ & 1 & & & \\
\hline 8 & $0.316 *$ & $0.551 *$ & $0.428 *$ & $0.414 *$ & $0.474 *$ & $0.540 *$ & $0.588 *$ & 1 & & \\
\hline 9 & $0.422 *$ & $0.517 *$ & $0.323 *$ & 0.396* & $0.443^{*}$ & $0.521 *$ & $0.483^{*}$ & $0.502 *$ & 1 & \\
\hline Total & $0.700 *$ & $0.747 *$ & $0.668 *$ & $0.755 *$ & $0.684 *$ & $0.768 *$ & $0.810 *$ & $0.735 *$ & $0.687 *$ & 1 \\
\hline
\end{tabular}

BDI-13 = short form of the Beck Depression Inventory-13; PHQ-9 = Patient Health Questionnaire-9; PHQ-15 = Patient Health Questionnaire-15; WHO-5 = World Health Organization-five Well-Being Index.

* Significant at 0.01.

+ Significant at 0.05 .

Table 3 - Factor loadings (>0.5) of the Patient Health Questionnaire-9 in 130 Iranian psychiatric outpatients

\begin{tabular}{|c|c|}
\hline Patient Health Questionnaire-9 items & Component \\
\hline Over the last 2 weeks, how often have you been bothered by any of the following problems? & 1 \\
\hline 1. Little interest or pleasure in doing things. & 0.69 \\
\hline 2. Feeling down, depressed, or hopeless. & 0.74 \\
\hline 3. Trouble falling or staying asleep, or sleeping too much. & 0.65 \\
\hline 4. Feeling tired or having little energy. & 0.75 \\
\hline 5. Poor appetite or overeating. & 0.68 \\
\hline 6. Feeling bad about yourself, or that you are a failure, or have let yourself or your family down. & 0.77 \\
\hline 7. Trouble concentrating on things, such as reading the newspaper or watching television. & 0.81 \\
\hline $\begin{array}{l}\text { 8. Moving or speaking so slowly that other people could have noticed. or the opposite - being so fidgety or restless } \\
\text { that you have been moving around a lot more than usual. }\end{array}$ & 0.73 \\
\hline 9. Thoughts that you would be better off dead, or of hurting yourself in some way. & 0.70 \\
\hline Eigenvalue & 4.79 \\
\hline$\%$ of variance & 53.26 \\
\hline
\end{tabular}

Factor 1 (items: $1,2,3,4,5,6,7,8$, and 9): General depression.

148 - Trends Psychiatry Psychother. 2018;40(2) 
9 correlated with the Health Assessment Questionnaire Disability Index (HAQDI), positively correlated at 0.73 with the Symptom Checklist-90-Revised (SCL-90-R) - Depression, negatively correlated at -0.57 with the World Health Organization Quality of Life instrumentAbbreviated version (WHOQOL-Bref) and with Mental Health-Related Quality of Life (HRQOL) scales among Greek rheumatologic patients. In the study by Monteiro et al., ${ }^{77}$ the PHQ-9 showed high to moderate convergent validity with the BDI $(r=0.85 ; \mathrm{p}<0.01)$, with HADS-Anxiety $(r=0.61 ; \mathrm{p}<0.01)$, and with HADS-Depression $(r=0.59$; $\mathrm{p}<0.01$ ) among Portuguese university students. Zhong et al. $^{79}$ reported that the PHQ-9 correlated at 0.52 with the Edinburgh Postnatal Depression Scale (EPDS) among pregnant Peruvian women. The PHQ-9 also correlated at 0.62 with the Metacognitions Questionnaire-30 (MCQ-30) and at 0.73 with the Generalized Anxiety Disorder-7 (GAD7 ) in a Norwegian-speaking community sample. ${ }^{53} \mathrm{Wu}^{67}$ indicated that the PHQ-9 negatively correlated at -0.60 with WHO-5, at 0.61 with HADS-Anxiety, at 0.52 with HADS-Depression, and negatively correlated at -0.40 with the WHOQOL Short-form Version for Taiwan in patients with metabolic syndrome. Hanwella et al. ${ }^{46}$ found that the correlation between the PHQ- 9 and the CES-D was 0.87 in patients with MDD. Dadfar \& Lester ${ }^{80}$ reported that PHQ-9 correlated at 0.80 with the Patient Health Questionnaire-2 (PHQ-2) among Iranian psychiatric outpatients.

A single factor was identified, indicating good homogeneity of the items. Our findings are similar to previous studies that also obtained a single factor. ${ }^{33,48,70,74,79,81-83}$ Conversely, other studies yielded two factors. ${ }^{73,84-86}$ Differences may be explained by the fact that the PHQ-9 was used in patients with rheumatologic disorders and spinal cord injury with different religions and cultures, diverse rotation methods and factor loading coefficients. However, there are similar and different views regarding the factorial validity of the questionnaire and therefore about the use of the questionnaire in its proposed one-factor structure.

The present study has some limitations that should be taken into consideration. The study investigated the PHQ9 in a sample of non-hospitalized psychiatric patients, not in the community. Moreover, sample recruitment was not random, but rather by convenience, meaning that these findings cannot be generalized to other samples. Also, we did not follow the patients in order to evaluate therapy responses and feedbacks, so the clinical importance of the PHQ-9 was not investigated.

Despite these limitations, the present findings suggest that the PHQ-9 has a unidimensional structure, good validity and reliability, and is useful and effective in epidemiological and research settings. Based on previous literature and on the current data, we conclude that the PHQ-9 may have applicability in other contexts in the studied population, even though this still needs to be confirmed. The use of confirmatory factor analysis allowed the study to offer further explanation of the rationale for latent structures and the statistical methods used to investigate it. The PHQ-9 may provide an opportunity for researches to conduct cross-cultural comparisons, and future studies should be conducted with diverse populations and different sociodemographic backgrounds.

\section{Disclosure}

No conflicts of interest declared concerning the publication of this article.

\section{References}

1. U.S. Preventive Services Task Force (USPSTF). Screening for depression in adults [Internet]. 2017 [cited 2017 Aug 23]. https://www.uspreventiveservicestaskforce.org/Page/Name/ about-the-uspstf

2. American Psychiatric Association. Diagnostic and Statistical Manual of Mental Disorders, Fifth Edition (DSM-5). DSM development. Washington: APA; 2017.

3. Maurer DM. Screening for depression. Am Fam Physician. 2012;85:139-44.

4. Ahmadvand A, Sepehrmanesh Z, Ghoreishi FS, Afshinmajd S. Prevalence of psychiatric disorders in the general population of Kashan, Iran. Arch Iran Med. 2012;15:205-9.

5. Bakhtar $M$, Rezaeian $M$. The prevalence of suicide thoughts and attempted suicide plus their risk factors among Iranian students: a systematic review study. J Rafsanjan Uni Med Sci. 2017;15:106176.

6. Dadfar M, Lester D. Prevalence of personality disorders and clinical syndromes using the Millon Clinical Multiaxial Inventory III (MCMI-III) in an Iranian clinical sample. Int J Biomed Engin Clin Sci. 2016;1:17-28.

7. Nease DE Jr, Maloin JM. Depression screening: a practical strategy. J Fam Pract. 2003;52:118-24.

8. Spitzer RL, Williams JBW, Kroenke K, Linzer M, deGruy FV, Hahn SR, et al. Utility of a new procedure for diagnosing mental disorders in primary care: the PRIME-MD 1000 study. JAMA. 1994;272:1749-56.

9. Spitzer RL, Kroenke K, Williams JBW. Validation and utility of a self-report version of PRIME-MD: the PHQ Primary Care Study. Primary Care Evaluation of Mental Disorders. Patient Health Questionnaire. JAMA. 1999;282:1737-44.

10. Kroenke K, Spitzer RL, Williams JBW. The PHQ-9: validity of a brief depression severity measure. J Gen Intern Med. 2001;16:60613.

11. Kroenke K, Spitzer RL, Williams JBW, Löwe B. The Patient Health Questionnaire Somatic, Anxiety, and Depressive Symptom Scales: a systematic review. Gen Hosp Psychiatry. 2010;32:345-59.

12. Yazici Güleç $M$, Güleç $H$, Simşek G, Turhan $M$, Aydin Sünbül E. Psychometric properties of the Turkish version of the Patient Health Questionnaire-Somatic, Anxiety, and Depressive Symptoms. Compr Psychiatry. 2012;53:623-9.

13. Kroenke K, Spitzer RL. The PHQ-9: a new depression diagnostic and severity measure. Psychiatric Ann. 2002;32:509-21.

14. Williams JW, Noel PH, Cordes JA, Ramirez G, Pignone M. Is this patient clinically depressed? JAMA. 2002;287:1160-70.

15. Eack SM, Greeno CG, Lee BJ. Limitations of the Patient Health Questionnaire in identifying anxiety and depression: many cases are undetected. Res Soc Work Pract. 2006;16:625-31.

16. Meader N, Mitchell AJ, Chew-Graham C, Goldberg D, Rizzo M, Bird $\mathrm{V}$, et al. Case identification of depression in patients with chronic 
physical health problems: a diagnostic accuracy meta-analysis of 113 studies. Br J Gen Pract. 2011;61:808-20.

17. Choi SW, Schalet B, Cook KF, Cella D. Establishing a common metric for depressive symptoms: linking the BDI-II, CES-D, and PHQ-9 to PROMIS depression. Psychol Assess. 2014;26:513-27.

18. Löwe B, Unützer J, Callahan CM, Perkins $A J$, Kroenke K. Monitoring depression treatment outcomes with the Patient Health Questionnaire-9. Med Care. 2004;42:1194-1201.

19. Ell K, Quon B, Quinn DI, Dwight-Johnson M, Wells A, Lee PJ, et al. Improving treatment for depression among low-income patients with cancer: the design of the ADAPt-C study. Gen Hosp Psychiatry. 2007;29:223-31.

20. Cannon DS, Tiffany ST, Coon H, Scholand MB, McMahon WM, Leppert MF. The PHQ-9 as a brief assessment of lifetime major depression. Psychol Assess. 2007;19:247-51.

21. Rooney AG, McNamara S, Mackinnon M, Fraser M, Rampling $R$, Carson A, et al. Screening for major depressive disorder in adults with glioma using the PHQ-9: a comparison of patient versus proxy reports. J Neurooncol. 2013;113:49-55.

22. Santos IS, Tavares BF, Munhoz TN, Almeida LS, Silva NT, Tams BD, et al. Sensitivity and specificity of the Patient Health Questionnaire-9 (PHQ-9) among adults from the general population. Cad Saúde Pública. 2013;29:1533-43.

23. Thombs BD, Benedetti A, Kloda LA, Levis B, Nicolau I, Cuijpers P, et al. The diagnostic accuracy of the Patient Health Questionnaire-2 (PHQ-2), Patient Health Questionnaire-8 (PHQ-8), and Patient Health Questionnaire-9 (PHQ-9) for detecting major depression: protocol for a systematic review and individual patient data metaanalyses. Syst Rev. 2014;3;124.

24. Poots AJ, Green SA, Honeybourne E, Green J, Woodcock T, Barnes $R$, et al. Improving mental health outcomes: achieving equity through quality improvement. Int J Qual Health Care. 2014;26:198-204.

25. Li CM, Zhang X, Hoffman HJ, Cotch MF, Themann CL, Wilson MR. Hearing impairment associated with depression in US adults, National Health and Nutrition Examination Survey 2005-2010. JAMA Otolaryngol Head Neck Surg. 2014;140:293-302.

26. Kiely KM, Butterworth P. Validation of four measures of mental health against depression and generalized anxiety in a community based sample. Psychiatry Res. 2015;225:291-8.

27. Loeb D, Sieja A, Corral J, Zehnder NG, Guiton G, Nease DE. Evaluation of the role of training in the implementation of a depression screening and treatment protocol in 2 academic outpatient internal medicine clinics utilizing the electronic medical record. Am J Med Qual. 2015;30:359-66.

28. Pinto-Meza A, Serrano-Blanco A, Peñarrubia MT, Blanco E, Haro $\mathrm{JM}$. Assessing depression in primary care with the PHQ-9: can it be carried out over the telephone? J Gen Intern Med. 2005;20:73842.

29. Cameron IM, Crawford JR, Lawton K, Reid IC. Psychometric comparison of PHQ-9 and HADS for measuring depression severity in primary care. $\mathrm{Br}$ ] Gen Pract. 2008;58:32-6.

30. Diez-Quevedo C, Rangil T, Sanchez-Planell L, Kroenke K, Spitzer RL. Validation and utility of the Patient Health Questionnaire in diagnosing mental disorders in 1003 General Hospital Spanish Inpatients. Psychosom Med. 2001;63:679-86.

31. Liu SI, Yeh ZT, Huang HC, Sun FJ, Tjung JJ, Hwang LC, et al. Validation of Patient Health Questionnaire for depression screening among primary care patients in Taiwan. Compr Psychiatry. 2011;52:96-101.

32. de Lima Osório F, Vilela Mendes A, Crippa JA, Loureiro SR. Study of the discriminative validity of the PHQ-9 and PHQ-2 in a sample of Brazilian women in the context of primary health care. Perspect Psychiatr Care. 2009;45:216-27.

33. Yu X, Tam WW, Wong PT, Lam TH, Stewart SM. The Patient Health Questionnaire-9 for measuring depressive symptoms among the general population in Hong Kong. Compr Psychiatry. 2012;53:95102.

34. Adewuya AO, Ola BA, Afolabi OO. Validity of the Patient Health Questionnaire (PHQ-9) as a screening tool for depression amongst Nigerian university students. J Affect Disord. 2006;96:89-93.

35. Han C, Jo SA, Kwak JH, Pae CU, Steffens D, Jo I, et al. Validation of the Patient Health Questionnaire-9 Korean version in the elderly population: the Asian geriatric study. Compr Psychiatry. 2008;49:218-23.

36. Lotrakul M, Sumrithe S, Saipanish R. Reliability and validity of the Thai version of the PHQ-9. BMC Psychiatry. 2008;8:46.

37. Karekla M, Pilipenko N, Feldman J. Patient Health Questionnaire: Greek language validation and subscale factor structure. Compr Psychiatry. 2012;53:1217-26.
38. Becker S, Zaid KA, Faris EAF. Screening for somatization and depression in Saudi Arabia: a validation study of the PHQ in primary care. Int J Psychiatry Med. 2002;32:271-83.

39. Yeung A, Fung F, Yu SC, Vorono S, Ly M, Wu S, et al. Validation of the Patient Health Questionnaire- 9 for depression screening among Chinese Americans. Compr Psychiatry. 2008;49:211-7.

40. Donlan W, Lee J. Screening for depression among indigenous Mexican migrant farmworkers using the Patient Health Questionnaire-9. Psychol Rep. 2010;106:419-32.

41. Carballeira $Y$, Dumont $P$, Borgacci $S$, Rentsch $D$, de Tonnac N, Archinard $M$, et al. Criterion validity of the French version of Patient Health Questionnaire (PHQ) in a hospital department of internal medicine. Psychol Psychother. 2007;80:69-77.

42. Yazici Güleç $M$, Güleç $H$, Simşek G, Turhan M, Aydin Sünbül E. Psychometric properties of the Turkish version of the Patient Health Questionnaire-Somatic, Anxiety, and Depressive Symptoms. Compr Psychiatry. 2012;53:623-9.

43. Omoro SA, Fann JR, Weymuller EA, Macharia IM, Yueh B. Swahili translation and validation of the Patient Health Questionnaire- 9 depression scale in the Kenyan head and neck cancer patient population. Int J Psychiatry Med. 2006;36:367-81.

44. Rogers KD, Young A, Lovell K, Campbell M, Scott PR, Kendal $\mathrm{S}$. The British sign language versions of the Patient Health Questionnaire, the Generalized Anxiety Disorder 7-Item Scale, and the Work and Social Adjustment Scale. J Deaf Stud Deaf Educ. 2013;18:110-22.

45. Brown AD, Mentha R, Rowley KG, Skinner T, Davy C, O’Dea K. Depression in Aboriginal men in central Australia: adaptation of the Patient Health Questionnaire 9. BMC Psychiatry. 2013;13:271.

46. Hanwella R, Ekanayake S, de Silva VA. The validity and reliability of the Sinhala translation of the Patient Health Questionnaire (PHQ9) and PHQ-2 screener. Dep Res Treat. 2014;2014:768978.

47. Gothwal VK, Bagga DK, Bharani S, Sumalini R, Reddy SP. The Patient Health Questionnaire-9: validation among patients with glaucoma. PLoS One. 2014;9:101295.

48. Torres A, Monteiro S, Pereira A, Albuquerque E. Reliability and validity of the PHQ-9 in Portuguese women with breast cancer EpSBS. 2016;2016:411-23. http://dx.doi.org/10.15405/ epsbs.2016.07.02.39

49. Khamseh $M E$, Baradaran $H R$, Javanbakht $A$, Mirghorbani $M$ Yadollahi Z, Malek M. Comparison of the CES-D and PHQ-9 depression scales in people with type 2 diabetes in Tehran, Iran. BMC Psychiatry. 2011;16:61.

50. Kroenke K. Spitzer RL, Williams JBW. The Patient Health Questionnaire-2: validity of a two-item depression screener. Med Care. 2003;41:1284-92.

51. American Psychological Association. Patient Health Questionnaire (PHQ-9 \& PHQ-2) construct: depressive symptoms. Washington: APA; 2015.

52. Xiong N, Fritzsche $K$, Wei J, Hong $X$, Leonhart R, Zhao $X$, et al. Validation of patient health questionnaire (PHQ) for major depression in Chinese outpatients with multiple somatic symptoms: a multicenter cross-sectional study. J Affect Disord. 2015; 174:636-43.

53. Solem S, Thunes SS, Hjemdal O, Hagen R, Wells A. A metacognitive perspective on mindfulness: an empirical investigation. BMC Psychol. 2015;3:24.

54. Han C, Pae CU, Patkar AA, Masand PS, Kim KW, Joe SH, et al. Psychometric properties of the Patient Health Questionnaire-15 (PHQ-15) for measuring the somatic symptoms of psychiatric outpatients. Psychosomatics. 2009;50:580-5.

55. Ros Montalbán S, Comas Vives A, Garcia-Garcia M. Validation of the Spanish Version of the PHQ-15 Questionnaire for the evaluation of physical symptoms in patients with depression and/ or anxiety disorders: DEPRE-SOMA study. Actas Esp Psiquiatr. 2010;38:345-57.

56. Lee $\mathrm{S}, \mathrm{Ma} \mathrm{YL}$, Tsang A. Psychometric properties of the Chinese 15-item Patient Health Questionnaire in the general population of Hong Kong. J Psychosom Res. 2011;71:69-73.

57. Körber S, Frieser D, Steinbrecher N, Hiller W. Classification characteristics of the Patient Health Questionnaire-15 for screening somatoform disorders in a primary care setting. J Psychosom Res. 2011;71:142-7.

58. de Vroege L, Hoedeman R, Nuyen J, Sijtsma K, van der FeltzCornelis CM. Validation of the PHQ-15 for somatoform disorder in the occupational health care setting. J Occup Rehabil. 2012;22:51-8.

59. Kocalevent RD, Hinz A, Brähler E. Standardization of a screening instrument (PHQ-15) for somatization syndromes in the general population. BMC Psychiatry. 2013;13:91. 
60. Qian J, Ren ZQ, Yu DH, He XY, Li CB. The value of the Patient Health Questionnaire-15 (PHQ-15) for screening somatic symptoms in general hospital. Chin Ment Health J. 2014;28:173-8.

61. Gierk B, Kohlmann S, Toussaint A, Wahl I, Brünahl CA, Murray $A M$, et al. Assessing somatic symptom burden: a psychometric comparison of the Patient Health Questionnaire-15 (PHQ-15) and the Somatic Symptom Scale-8 (SSS-8). J Psychosom Res. 2015;78:352-5.

62. Zhang $L$, Fritzsche $K$, Liu $Y$, Wang J, Huang $M$, Wang $Y$, et al. Validation of the Chinese version of the PHQ-15 in a tertiary hospital. BMC Psychiatry. 2016;16:89.

63. Topp CW, Østergaard SD, Søndergaard S, Bech P. The WHO-5 WellBeing Index: a systematic review of the literature. Psychother Psychosom. 2015;84:167-76.

64. de Wit M, Pouwer F, Gemke RJ, Delemarre-van de Waal HA, Snoek FJ. Validation of the WHO-5 Well-Being Index in adolescents with type 1 diabetes. Diabetes Care. 2007;30:2003-6.

65. Hajos TR, Pouwer F, Skovlund SE, Den Oudsten BL, GeelhoedDuijvestijn $\mathrm{PH}$, Tack $\mathrm{CJ}$, et al. Psychometric and screening properties of the WHO-5 Well-Being Index in adult outpatients with Type 1 or Type 2 diabetes mellitus. Diabet Med. 2013;30:639.

66. Saipanish $\mathrm{R}$, Lotrakul M, Sumrithe $\mathrm{S}$. Reliability and validity of the Thai version of the WHO-Five Well-Being Index in primary care patients. Psychiatry Clin Neurosc. 2009;63:141-6.

67. Wu SFV. Rapid screening of psychological well-being of patients with chronic illness: reliability and validity test on WHO-5 and PHQ-9 scales. Dep Res Treat. 2014;2014:239490.

68. Dadfar M, Momeni Safarabad N, Asgharnejad Farid AA, Nemati Shirzy M, Ghazie pour Abarghouie F. Reliability, validity, and factorial structure of the World Health Organization-5 WellBeing Index (WHO-5) in Iranian psychiatric outpatients. Trends Psychiatry Psychother. 2018;40(2):000-000.

69. Dadfar M, Kalibatseva Z. Psychometric properties of the Persian version of the short Beck Depression Inventory with Iranian psychiatric outpatients. Scientifica. 2016;2016:8196463.

70. Lee PW, Schulberg HC, Raue PJ, Kroenke K. Concordance between the PHQ-9 and the HSCL-20. J Affect Disord. 2007;99:139-45.

71. Cameron IM, Crawford JR, Lawton K, Reid IC. Psychometric comparison of PHQ-9 and HADS for measuring depression severity in primary care. $\mathrm{Br}$ J Gen Pract. 2008;58:32-6.

72. van Steenbergen-Weijenburg $K M$, de Vroege $L$, Ploeger $R R$, Brals JW, Vloedbeld MG, Veneman TF, et al. Validation of the PHQ-9 as a screening instrument for depression in diabetes patients in specialized outpatient clinics. BMC Health Serv Res. 2010;10:235.

73. Hyphantis $T$, Kotsis $K$, Voulgari PV, Tsifetaki $N$, Creed $F$, Drosos AA. Diagnostic accuracy, internal consistency, and convergent validity of the Greek version of the patient health questionnaire 9 in diagnosing depression in rheumatologic disorders. Arthritis Care Res (Hoboken). 2011;63:1313-21.
74. Zhong Q, Gelaye B, Fann JR, Sanchez SE, Williams MA. Crosscultural validity of the Spanish version of PHQ-9 among pregnant Peruvian women: a Rasch item response theory analysis. J Affect Disord. 2014;158:148-53.

75. Dum M, Pickren J, Sobell LC, Sobell MB. Comparing the BDI-II and the PHQ-9 with outpatient substance abusers. Addict Behav. 2008;33:381-7.

76. Zuithoff NP, Vergouwe $Y$, King M, Nazareth I, van Wezep MJ, Moons KG, Geerlings MI. The Patient Health Questionnaire-9 for detection of major depressive disorder in primary care: consequences of current thresholds in a cross sectional study. BMC Fam Pract. 2010;11:98.

77. Monteiro S, Torres A, Pereira A, Albuquerque E, Morgadinho R. 2077- Preliminary validation study of a Portuguese version of the patient health questionnaire (PHQ-9). Eur Psychiatry. 2013:28:12-9.

78. Torres A, Venâncio J. Effects of an innovative group program of multisensory stimulation of older adults. EpSBS. 2016;2016:38796. http://dx.doi.org/10.15405/epsbs.2016.07.02.37

79. Zhong Q, Gelaye B, Rondon M, Sánchez SE, García PJ, Sánchez E, et al. Comparative performance of Patient Health Questionnaire- 9 and Edinburgh Postnatal Depression Scale for screening antepartum depression. J Affect Disord. 2014;162:1-7.

80. Dadfar M, Lester D. Psychometric characteristics of Patient Health Questionnaire-2 (PHQ-2) in Iranian psychiatric outpatients. Austin J Psychiatry Behav Sci. 2017;4:1059.

81. Huang FY, Chung H, Kroenke K, Delucchi KL, Spitzer RL. Using the Patient Health Questionnaire-9 to measure depression among racially and ethnically diverse primary care patients. J Gen Intern Med. 2006;21:547-52.

82. Graves $\mathrm{DE}$, Bombardier $\mathrm{CH}$. Improving the efficiency of screening for major depression in people with spinal cord injury. J Spinal Cord Med. 2008;31:177-84.

83. Hansson M, Chotai J, Nordstom A, Bodlund O. Comparison of two self rating scales to detect depression: HADS and $\mathrm{PHQ}-9 . \mathrm{Br}$ J Genl Pract. 2009;59:283-8.

84. Kalpakjian $\mathrm{CZ}$, Toussaint $\mathrm{LL}$, Albright $\mathrm{KJ}$, Bombardier $\mathrm{CH}$, Krause JK, Tate DG. Patient Health Questionnaire-9 in spinal cord injury: an examination of factor structure as related to gender. J Spinal Cord Med. 2009;32:147-56.

85. Krause JS, Reed KS, McArdle JJ. Factor structure and predictive validity of somatic and nonsomatic symptoms from the Patient Health Questionnaire-9: a longitudinal study after spinal cord injury. Arch Phys Med Rehabil. 2010;91:1218-24.

86. Richardson EJ Richards JS. Factor structure of the PHQ-9 screen for depression across time since injury among persons with spinal cord injury. Rehabil Psychol. 2008;53:243-9.

\section{Correspondence:}

mahboubehdadfar@yahoo.com 